\title{
O esporte na política colonial portuguesa: o Boletim Geral do Ultramar
}

\author{
Victor Andrade de Melo[1] e Marcelo Bittencourt[2]
}

\begin{abstract}
Resumo
O artigo tem por objetivo discutir como o tema esporte foi tratado no Boletim Geral do Ultramar, uma publicação oficial do governo português. A partir de um panorama das relações estabelecidas entre Portugal e suas colônias no âmbito da prática esportiva, após a Segunda Guerra Mundial, foram analisadas as representações acerca do esporte mobilizadas pela metrópole, lançando um novo olhar sobre sua política colonial.
\end{abstract}

Palavras-chave: esporte; África; Portugal.

\section{El deporte en la política colonial portuguesa: Boletim Geral do Ultramar}

\section{Resumen}

El artículo tubo como objetivo discutir el tratamiento del tema del deporte en el Boletim Geral do Ultramar (Boletín General de Ultramar), una publicación oficial del gobierno portugués. Desde una visión general de las relaciones entre Portugal y sus colonias en el contexto del deporte, en el pos Segunda Guerra Mundial, se analizaron las representaciones sobre el deporte movilizadas por la metrópoli, lanzando una nueva mirada a su política colonial.

Palabras clave: deporte; África; Portugal.

\section{Sports in the colonial Portuguese politics: Boletim Geral do Ultramar}

\begin{abstract}
The article aimed at discussing the treatment of the theme sport in the Boletim Geral do Ultramar (Overseas General Bulletin), an official publication launched by the Portuguese government. From an overview of the relations between Portugal and its colonies in the context of sports, in the post World War II, we analyzed the representations on the sport mobilized by such metropolis, launching a new look at its colonial policy.
\end{abstract}

Keywords: sport; Africa; Portugal.

\section{Le sport dans la politique coloniale portugaise: Boletim Geral do Ultramar}

\section{Résumé}

Le but de cette article est de discuter comme le thème of sport a eté traité dans le Boletim Geral do Ultramar (Bulletin Général d'outre-mer), une publication officielle du gouvernement Portugais. À partir de un aperçu des relations entre Portugal e ses colonies em ce que concerne les pratiques sportives après la seconde guerre mondiale, les representations du sport dans la mètropole ont été analysés, et ainsi un nouveau regard a eté lancé sur la politique coloniale.

Mots-clés: sport; Afrique; Portugal. 
A dialética das relações entre a globalização, a identidade nacional e a xenofobia é enfaticamente demonstrada pela atividade pública que combina esses três elementos: o futebol. ${ }^{1}$

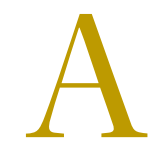

pós a Segunda Guerra Mundial, o esporte ocupou um espaço pronunciado no quadro sociocultural global, tendo sido constantemente mobilizado ao redor de questões locais (de forma denotada no âmbito dos clubes), temas nacionais (sobretudo no que se refere à construção de discursos identitários) e projeções internacionais. Nesta, destacou-se o protagonismo desempenhado pelas competições e entidades mundiais, como o Comitê Olímpico Internacional (COI) e a Federação Internacional de Futebol (FIFA).

Uma combinação de fatores auxilia na compreensão dessa presença e importância: sua instrumentalização política em um cenário de Guerra Fria, emulando e dramatizando a bipolaridade do mundo pós-guerra; sua definitiva inserção na crescente indústria do entretenimento, destacando-se o fato de ter progressivamente se tornado um dos principais produtos televisivos; a percepção que sua capacidade de mobilização poderia ser utilizada para fins outros que não os da prática esportiva em si, algo que se tornou mais explícito com os usos que foram feitos por regimes autoritários nas décadas de 1930 e $1940 .^{2}$

Portugal, ainda que a princípio não tenha estabelecido relações mais intensas com o esporte, ${ }^{3}$ não esteve alheio à nova presença da prática no cenário internacional. Para Drumond, ${ }^{4}$ no período de 1930 a 1945, a prática foi mobilizada pelo Estado Novo, pronunciadamente com o intuito de promover o aperfeiçoamento eugênico e cívico da juventude, assim como de controlar o tempo dos trabalhadores.

A partir da década de 1950, tornou-se mais evidente a mobilização do esporte com o objetivo de construir discursos sobre a identidade nacional portuguesa. Alguns fatores internos que ajudam a explicar a intensificação da associação do regime com a prática devem ser destacados, especialmente, a avaliação da validade das experiências implementadas nas décadas de $1930 \mathrm{e}$ 1940 e os bons resultados obtidos por algumas equipes esportivas representativas do país. Pode-se destacar as conquistas da seleção nacional de hóquei em patins ${ }^{5}$ e do Sport Lisboa e Benfica, ${ }^{6}$ capitaneado por um dos maiores ídolos

\footnotetext{
'Eric Hobsbawm, Globalização, democracia e terrorismo, São Paulo, Companhia das Letras, 1997, p. 92. 2Pierre Arnaud, Jim Riordan (org), Sport and international politics: the impact of fascism and communism on sport, London, Taylor \& Francis, 1998; Teresa Aja (org.), Sport y autoritarismo: la utilización del deporte por el comunismo y el fascismo, Madrid, Alianza Editorial, 2002.

Victor Andrade de Melo, “Esporte e artes plásticas em Portugal: Amadeo de Souza-Cardoso", Revista Portuguesa de Ciências do Desporto, vol. 10, n. 1, Porto, 2010, p. 191-199.

4Maurício Drumond, Ao bem do desporto e ao bem da nação: relações entre desporto e política no Estado Novo (1933-1945), Rio de Janeiro, 2012, mimeo.

${ }^{5}$ A seleção portuguesa sagrou-se campeã mundial de 1947 a 1950, 1952, de 1956 a 1962, 1968, entre outros. A hegemonia na Europa é ainda maior: conquistou os campeonatos disputados entre 1959 e 1977, com exceção de 1969, vencido pela Espanha.

${ }^{6}$ A equipe conquistou a Taça dos Clubes Campeões Europeus, em 1961 e 1962. Foi ainda, na mesma década, duas vezes vice-campeã da Taça Intercontinental, disputada com o time vencedor da Copa Libertadores da América, que reunia países da América do Sul: em 1961 foi derrotada pelo Peñarol do Uruguai e em 1962 pelo Santos do Brasil. Foi também finalista não vitoriosa da Taça dos Clubes Campeões Europeus em 1963, 1965 e 1968.
} 
da história do futebol português, o moçambicano Eusébio, considerado um dos responsáveis pelo melhor resultado do escrete nacional em uma Copa do Mundo (terceiro lugar em 1966, na Inglaterra). Para alguns autores, é inegável que essa modalidade integrava, naquele momento, as estratégias de propaganda do regime de Salazar, por eles denominado de 3fs: Futebol, Fado e Fátima. ${ }^{7}$

Essa relação mais constante com o esporte também tinha ligação com o mau momento enfrentado pelo país no cenário diplomático internacional. A estratégia de defender que Portugal possuía territórios pluricontinentais, e não colônias, não conseguia alcançar apoios para além dos tradicionais aliados da Organização do Tratado do Atlântico Norte (OTAN) e de dois importantes países do Atlântico Sul (Brasil, sua ex-colônia, e África do Sul, vizinho de suas colônias na África Austral e em crescente isolamento internacional em função da institucionalização do apartheid).

Por outro lado, os embates políticos travados pelos Estados Unidos e pela URSS na Organização das Nações Unidas (ONU) e a imagem conservadora do regime autoritário português adensavam os obstáculos às suas pretensões internacionais. Diante de tal quadro, é fácil entender a razão de Portugal ter sido aceito na ONU apenas em 1955, dez anos depois da criação da entidade.

Além disso, desde o início da década de 1960, especialmente após a explosão da guerrilha no Norte de Angola, em 1961, aumentou a pressão de alguns membros da comunidade internacional para a abertura de negociações com os movimentos de libertação e a construção de um processo de independência negociada das suas colônias na África, proposta considerada inadmissível pelo Estado Novo, o que contribuiria sobremaneira para seu isolamento. ${ }^{8}$

A aproximação com as entidades esportivas internacionais permitia ao regime a construção de uma imagem de que desejava participar, como outras nações, da fraternidade mundial que marcava os discursos no pós-guerra. Além disso, poderia ser um eficiente mecanismo para dar visibilidade aos supostos benefícios que propiciava aos seus territórios espalhados pelo mundo.

A mobilização do esporte pelo regime português tinha também, portanto, relação com suas estratégias para manter suas possessões na África e na Ásia. Como argumentam Bittencourt ${ }^{9}$ e Melo, ${ }^{10}$ o regime passou a utilizar a prática a fim de exaltar uma suposta identidade imperial, um sinal de que construíra uma nação "civilizada" fruto dos encontros inter-raciais. Tratava-se de uma visão construída e plenamente referendada pelo, na ocasião tão em voga, uso do luso-tropicalismo freireano. Como lembra Castelo, essa referência:

\footnotetext{
'inventada' com base em pressupostos históricos e numa imagem essencialista da personalidade do povo português, além de ter servido a interesses políticos-ideológicos conjunturais durante o Estado Novo, ajudou a perpetuar uma imagem mítica
}

\footnotetext{
${ }^{7}$ João Nuno Coelho, Francisco Pinheiro, A paixão do povo: história do futebol em Portugal, Porto, Afrontamento, 2002; Ricardo Serrado, O jogo de Salazar: a política e o futebol no Estado Novo, Alfragide, Casa das Letras, 2009. ${ }^{8}$ Fernando Tavares Pimenta, Portugal e o século XX: Estado-Império e descolonização (1890-1975), Lisboa, Edições Afrontamento, 2010.

${ }^{9}$ Marcelo Bittencourt, "Jogando no campo do inimigo: futebol e política em Angola", In: Victor Andrade de Melo, Marcelo Bittencourt, Augusto Nascimento (orgs.), Mais do que um jogo: o esporte no continente africano, Rio de Janeiro, Apicuri, 2010, p. 101-132

10Victor Andrade de Melo, Pequenas grandes representações do Império Português: a série postal "modalidades desportivas", Rio de Janeiro, 2012, mimeo.
} 
da identidade cultural portuguesa, concedendo-lhe autoridade 'científica' de que até aí não dispunha. ${ }^{11}$

Como terá se manifestado esse novo relacionamento nos boletins oficiais do governo português dedicados às colônias? Este estudo tem por objetivo discutir o trato do tema esporte no Boletim Geral do Ultramar. ${ }^{12}$ Por meio da análise desse periódico, espera-se traçar um panorama das relações estabelecidas entre Portugal e suas colônias no âmbito da prática esportiva. O principal intuito é aprofundar a compreensão sobre as representações acerca do esporte mobilizadas pela metrópole, lançando um novo olhar sobre sua política colonial.

O boletim começou a ser publicado em junho de 1925, com o nome de Boletim da Agência Geral das Colônias. A denominação foi alterada em 1935, para Boletim Geral das Colônias, e novamente, em definitivo, em 1951, quando passou a se chamar Boletim Geral do Ultramar. A última alteração foi motivada pela mudança na legislação colonial, que transformou as colônias em províncias ultramarinas, supostamente indicando que estas passaram a ser parte indivisível do Império Português.

O objetivo do periódico foi sempre o mesmo, estabelecer uma relação mais explícita com as colônias, variando, contudo, as ênfases e os enfoques que a ideia adquiriu no decorrer do tempo. A publicação, de qualquer forma, sempre foi composta por estudos/ensaios a respeito das peculiaridades dos territórios ultramarinos, posicionamentos oficiais e por uma parte noticiosa. Como bem resumiu Marroni:

\begin{abstract}
A publicação constitui-se como veículo de propaganda e informação mensal das colónias e para as colónias, pelo conteúdo informativo, pelos trabalhos técnicos, oficiais e particulares, pelos dados de arquivo e de estatística, em áreas ou serviços como agricultura, caminhos-de-ferro, meteorologia, obras públicas, portos, saúde, veterinária e outras, não especificadas. ${ }^{13}$
\end{abstract}

É sobre esse material, um olhar oficial sobre os territórios ultramarinos, que vamos nos debruçar. Trata-se, portanto, de assumidamente prospectar algo dos posicionamentos metropolitanos sobre o tema.

\title{
Uma nova legislação, uma nova atitude
}

O novo interesse governamental em investir no esporte e na educação física manifesta-se claramente na mudança da legislação. Em 1945, foram criados os Conselhos de Desportos, órgãos orientadores da prática, que funcionaram de forma desigual nas distintas localidades. ${ }^{14}$

\footnotetext{
"Cláudia Castelo, O modo português de estar no mundo: o luso-tropicalismo e a ideologia colonial portuguesa, Porto, Afrontamento, 1998, p. 14.

${ }^{12}$ Por restrições de espaço, não será abordada a presença do esporte em periódicos semelhantes publicados nas colônias, como o Boletim Cultural da Guiné Portuguesa, o Boletim Cultural da Câmara Municipal de Luanda e o Cabo Verde - Boletim de Informação e Propaganda. Trata-se de material de grande utilidade para ampliar o olhar sobre a presença da prática no âmbito da política colonial.

${ }_{13}^{13}$ Maria Luísa de Castro Marroni, Os outros e a construção da Escola Colonial Portuguesa no Boletim Geral das Colónias - 1925-1951, Dissertação de Mestrado em História e Educação, Faculdade de Letras da Universidade do Porto, Porto, 2008, p. 40.

${ }^{14} U$ m exemplo de atuação ativa pode ser encontrado na Guiné-Bissau, à época Guiné Portuguesa, no período em que Sarmento Rodrigues foi governador-geral de 1945 a 1949.
} 
A Lei 2.083, de 15 de junho de 1956, que "promulga as normas relativas às actividades gimnodesportivas nas províncias ultramarinas", estabelece novas e mais completas instruções a serem seguidas pelo Ministério do Ultramar, designado como responsável por sua execução. ${ }^{15}$ Entre outras decisões, instituem-se os Conselhos Provinciais de Educação Física como instâncias responsáveis pela implementação de estímulos à prática, usando para tal uma série de ferramentas que a legislação criava.

O novo interesse governamental transparece nas páginas do periódico, perceptível até mesmo no fato de que a partir de então começaram a ser mais constantemente publicadas informações sobre a prática esportiva.

A primeira vez que o tema apareceu no Boletim Geral do Ultramar, ainda denominado Boletim da Agência Geral das Colônias, foi em 1929, com a publicação de trechos de um livro de T. Alexander Barns, nos quais eram exaltadas as condições de Angola para receber interessados na prática da caça: "O transporte é fácil e razoavelmente barato, podendo mesmo, com efeito, dizer o autor que Angola, sob este ponto de vista, é a melhor colônia que ele conhece para o sportman.$^{16}$ Esse mesmo assunto retornou às páginas do periódico no ano seguinte, ${ }^{17}$ reforçando-se a ideia e apresentando-se mais informações de como o território angolano é propício aos caçadores "esportivos". ${ }^{8}$

Podemos perceber que o conceito de esporte se afasta daquele usualmente reconhecido, bem como estava relacionado a uma alternativa econômica que constantemente frequentará as páginas do periódico como uma saída rentável para as colônias: o turismo. Futuramente, no que se refere à prática esportiva, essa expectativa será observável ao redor do golfe em Cabo Verde, aproveitando-se da antiga tradição da modalidade, que por lá existia desde o século XIX. ${ }^{19}$

Em 1934, o tema já era tratado em seu sentido moderno. Informa-se que, no importante Congresso Desportivo realizado em Lisboa, ${ }^{20}$ foi sugerida a realização dos Primeiros Jogos Imperiais Portugueses, a exemplo do que estavam prevendo os britânicos. Foram apresentadas as decisões de uma seção dedicada a discutir os contatos esportivos entre a metrópole e as colônias, relatada por Salazar Carreira, ex-atleta, dirigente esportivo e um dos homens fortes do esporte no Estado Novo. Para ele, tal investimento era um

fator importantíssimo de portuguesismo, dando a esse termo o sentido da criação de um espírito nacional idêntico em todos os cidadãos portugueses espalhados pelos diversos territórios de domínio lusitano. ${ }^{21}$

Ainda era cedo para que a ideia fosse efetivamente implementada, assim como o era para a adoção do luso-tropicalismo pelo Estado Novo. O regime,

\footnotetext{
${ }^{15}$ Diário do Governo, número 122, série I, Lisboa, sexta-feira, 15 de junho de 1956.

${ }^{16}$ Boletim da Agência Geral das Colónias, vol. 5, n. 47, Lisboa, 1929, p. 320.

${ }^{17}$ Boletim da Agência Geral das Colónias, vol. 6, n. 56, Lisboa, 1930, p. 220

${ }^{18}$ Silvio Correa discutiu a interessante relação entre os adeptos da caça esportiva e as primeiras ações preservacionistas no continente africano em "Caça e preservação da vida selvagem na África colonial", Esboços (UFSC), vol. 18, Florianópolis, 2011, p. 164-183.

${ }^{19}$ Victor Andrade de Melo, Jogos de identidade: o esporte em Cabo Verde, Rio de Janeiro, Apicuri, 2011.

${ }^{20}$ Para mais informações referentes ao mesmo, ver Maurício Drumond, Ao bem do desporto e ao bem da nação: relações entre desporto e política no Estado Novo (1933-1945), Rio de Janeiro, 2012, mimeo.

${ }^{21}$ Boletim da Agência Geral das Colónias, vol. 10, n. 103, Lisboa, 1934, p. 112-117. Salazar Carreira ainda enfatizou a necessidade de ampliar o intercâmbio esportivo entre a metrópole e as colônias, bem como de investir no aperfeiçoamento da organização e do corpo técnico das colônias.
} 
naquele momento, ainda parecia estar afinando suas políticas coloniais pelos exemplos das demais nações europeias.

Sinal evidente de tal precocidade é o fato de que o tema somente foi citado novamente no Boletim Geral em 1960, sendo noticiada a participação de atletas de Angola nos Jogos Luso-Brasileiros de Educação Física, realizados em Lisboa. As palavras do Ministro do Ultramar, Vasco Lopes Alves, ao receber esses competidores, exaltavam: "O desporto é uma base importante para bem servir ao país".22 A recepção foi marcada por discursos de enaltecimento do valor das atividades físicas para Portugal. Não restavam mais dúvidas, estavam em marcha um novo olhar e uma mobilização da prática esportiva.

De fato, na esteira das decisões metropolitanas, desde a década de 1950, melhor se organizaram federações, associações e clubes nas diversas colônias portuguesas. Anteriormente, cabia ao governo de cada colônia estimular ou não, ser mais ou menos permissivo em relação à prática. A nova legislação estabelecia bases mais seguras tanto para o estímulo quanto para o controle das organizações esportivas. ${ }^{23}$

Além disso, uma das ações metropolitanas que mais contribuiu para o desenvolvimento esportivo nas colônias foi a instituição das Apostas Mútuas Desportivas, mais conhecidas como Totobola, em 1961. Comemorou-se em um jornal moçambicano a chegada da loteria:

Não é segredo nem novidade para ninguém que os dinheiros de tão popular concurso vieram beneficiar, e em muito, a expansão do desporto e contribuir, fantasticamente, para a resolução de variadíssimos problemas. $\mathrm{O}$ desporto bem merecia tal ajuda. ${ }^{24}$

Em 1965, uma nova iniciativa contribuiu ainda mais para a organização esportiva nas colônias, a criação do Fundo do Fomento do Desporto, ${ }^{25}$ partindo do princípio de que:

Está fora de qualquer dúvida o interesse que o Governo vem de há muito manifestando pelo desenvolvimento da educação física e do desporto, factores da mais alta importância na formação dos jovens e no revigoramento e salutar distracção de todos.

Nesse contexto, uma das entidades portuguesas que mais se relacionava à política esportiva passou a atuar mais fortemente nas colônias, a Mocidade Portuguesa. ${ }^{26} \mathrm{~A}$ organização foi criada em 1936, mostrando claras inspirações fascistas, com o objetivo de "dar um enquadramento político e militar à juventude nacional, formando-a nos valores do regime e colocando-a a serviço de Salazar".27

Em sua linha de atuação, havia a compreensão de que os esportes e as atividades físicas eram importantes ferramentas para catequizar os jovens, convencendo-os de suas responsabilidades para com a manutenção da "grande nação

\footnotetext{
223oletim Geral do Uitramar, vol. 36, n. 422-423, Lisboa, ago./set. 1960, p. 350-352.

${ }^{23}$ Sobre o tema da repressão aos clubes africanos, ver Victor Andrade de Melo, Marcelo Bittencourt, "Sob suspeita: o controle dos clubes esportivos no contexto colonial português”, Tempo, vol. 18, n. 33, Niterói, 2012, p. $191-215$.

${ }^{24}$ Boletim Geral do Ultramar, vol. 41, n. 479, Lisboa, maio de 1965, p. 253.

25“Decreto-lei n. 46449”, Diário do Governo, n. 163, série I, Lisboa, 23 de julho de 1965, p. 1031

${ }^{26}$ Sobre a Mocidade Portuguesa, ver Irene Flunser Pimentel, Mocidade Portuguesa Feminina, Lisboa, A Esfera dos Livros, 2007; Joaquim Vieira, Mocidade Portuguesa, Lisboa, A Esfera dos Livros, 2008.

${ }^{27}$ Fernando Tavares Pimenta, Portugal e o século XX: Estado-Império e descolonização (1890-1975), Lisboa, Edições Afrontamento, 2010, p. 72
} 
Portugal". A entidade era uma das mensageiras da metrópole nas colônias: "é um gigante, que une, numa solidariedade inquebrantável, numa fraternidade absoluta, a mocidade portuguesa do continente, das ilhas e do ultramar".28

Pelas páginas do Boletim, foi possível acompanhar a atuação tanto da Mocidade Portuguesa quanto dos Conselhos Provinciais, acompanhando/ fiscalizando as agremiações/associações, gerenciando recursos e investindo em vários aspectos relativos ao incremento do esporte. Vejamos, por exemplo, uma de suas ações:

O Conselho Provincial de Educação Física e Desportos de Moçambique distribuiu um comunicado no qual dá conhecimento das organizações desportivas que serão subsidiadas por aquele organismo.

Nesse comunicado, refere-se, também, que a prioridade dada foi estabelecida em função de uma política de estruturação e desenvolvimento das modalidades de ginástica desportiva, atletismo, natação, ao nível nacional, e, em algumas modalidades, ao nível provincial. ${ }^{29}$

Outra iniciativa relevante foi o incentivo à formação de mão de obra qualificada, como, por exemplo, por meio da realização de cursos para treinadores de futebol, que acontecem nas colônias com professores da metrópole ou estrangeiros. Também foram conferidos subsídios para que alguns técnicos fizessem cursos em Lisboa, bem como para a qualificação de árbitros. Chegou-se a aventar a criação, em Angola, de um Instituto de Educação Física destinado à formação de professores, à semelhança do seu congênere de Lisboa. ${ }^{30}$

$$
\begin{gathered}
\text { As palavras do Ministro do Ultramar, Vasco } \\
\text { Lopes Alves, ao receber esses competidores, } \\
\text { exaltavam: "O desporto é uma base impor- } \\
\text { tante para bem servir ao país }
\end{gathered}
$$

Esse investimento passou a ser necessário, devido ao fato de ter aumentado sensivelmente o número de competições organizadas nas províncias. Para que se tenha uma ideia, foram encontradas informações das seguintes modalidades: futebol, voleibol, basquetebol, ginástica, ciclismo, vela, remo, judô, natação, atletismo, hóquei (em campo e patins), tênis de mesa, handebol, automobilismo, motociclismo, tênis, golfe, tiro, aviação, luta, hipismo, remo, patinação e pesca desportiva.

Entre tantas contendas, pode-se destacar os Jogos Desportivos da Juventude de Angola, envolvendo participantes de todos os distritos da província. Esse tipo de evento também era uma forma do governo demonstrar que tinha controle sobre o território, afastando suspeitas quanto ao sucesso das iniciativas anticoloniais. Como de costume, as provas foram marcadas

${ }^{28}$ A Mocidade, ano 1, n. 2, 18 de dezembro de 1955, p. 3.

${ }^{29}$ Boletim Geral do Ultramar, vol. 44, n. 513, Lisboa, mar. 1968, p. 147

${ }^{30}$ Boletim Geral do Ultramar, vol. 41, n. 477, Lisboa, mar. 1965, p. 239. 
pela presença de autoridades, exibição dos símbolos nacionais e discursos exaltando a unidade nacional/imperial.

Outro aspecto que se observa regularmente nas páginas do Boletim é o investimento em construção e na reforma de instalações. Percebe-se uma crescente coparticipação entre Câmaras Municipais e Conselhos Provinciais de Educação Física, não poucas vezes sendo aportados recursos de outras fontes do governo metropolitano. Como resultados, foram tanto concedidos subsídios às agremiações quanto construídos mais equipamentos públicos. Vemos um exemplo dessa ação coordenada na construção de um parque de jogos em São Tomé e Príncipe. ${ }^{31}$

Enfim, no Boletim Geral do Ultramar nota-se a grande movimentação esportiva existente nas colônias, iniciativas que envolviam um razoável número de pessoas e exigiam uma boa organização. Não se pode dizer que tais ações atingiam todo o cômputo da população. Sabe-se que em grande parte congregavam majoritariamente colonos e brancos, e em menor escala a negros e mestiços, ainda que, de qualquer forma, esses também tivessem seus clubes e agremiações. O que é inegável é o crescimento da atenção que passou a ser dada ao assunto pelo governo metropolitano.

Cabe-nos, portanto, discutir a natureza desses relacionamentos e os discursos que envolviam tais iniciativas.

\section{Celebrando a nação nas contendas esportivas}

A fotografia, publicada na edição do Boletim Geral do Ultramar de julho de $1962,{ }^{32}$ um flagrante de uma visita do Benfica de Lisboa à Luanda, é uma expressão clara de como a prática esportiva era mobilizada para celebrar representações que atendiam às necessidades governamentais na luta pela manutenção do Império Português.

No centro da imagem observa-se o negro moçambicano Eusébio, bem vestido, câmera fotográfica ao redor do pescoço. Jovens e crianças, negros, brancos e

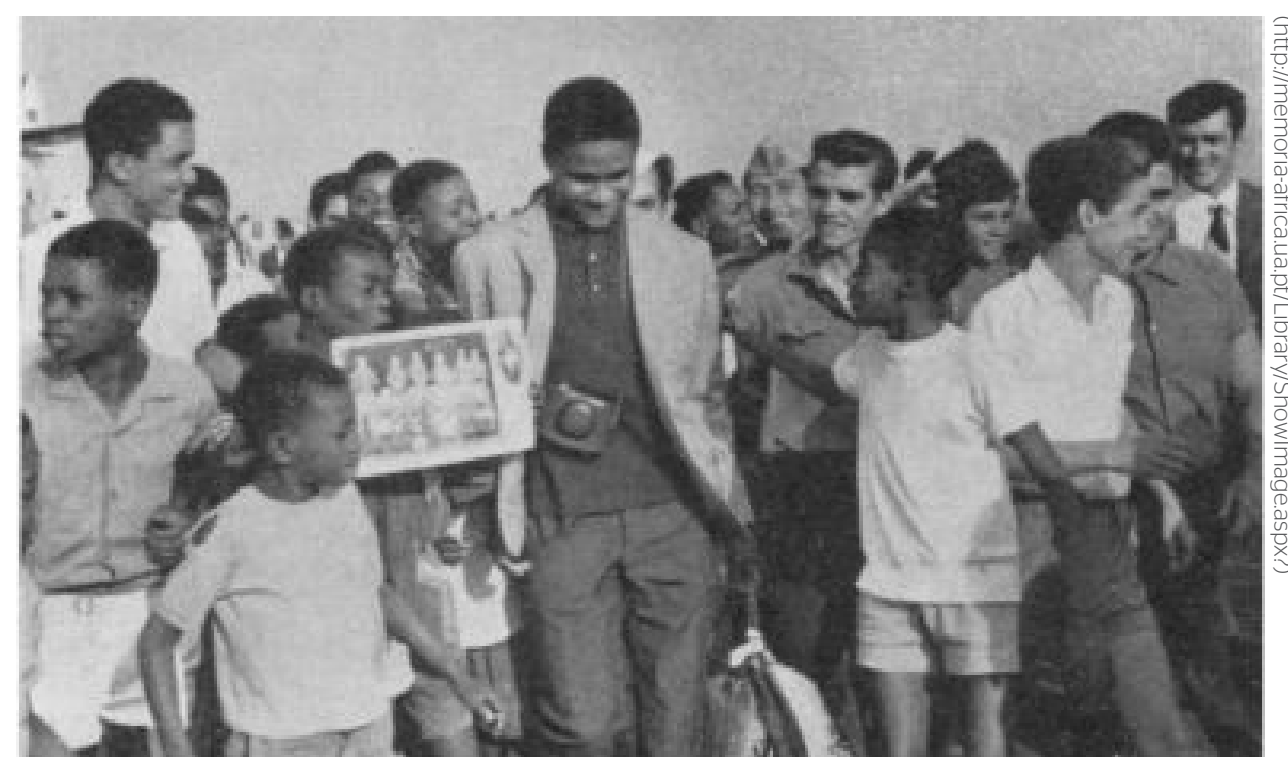

${ }^{31}$ Boletim Geral do Uitramar, vol. 38, n. 444, Lisboa, jun. 1962, p. 315 32Boletim Geral do Ultramar, vol. 38, n. 445, Lisboa, jul. 1962, p. 201. 
mestiços, com diferentes trajados cercam-no, todos com expressão de alegria, mesmo euforia, ao ver o craque. O rodapé da foto, expressando a mensagem imperial, poderia ser: 'a nação multirracial se irmana ao redor do ídolo que a representa'.

A notícia explicita o compromisso da vitoriosa equipe com a nação. Não se tratava apenas de uma excursão para fins de diversão, nem tampouco com intuito financeiro. Sem citar os conflitos coloniais, em especial a guerra anticolonial iniciada em 1961 em Angola, informava-se que o objetivo era colaborar para:

[...] Reunir receita líquida que contribua para a construção de um centro militar de recuperação dos inválidos do Exército e das restantes forças armadas. Na véspera da partida os elementos da equipe foram recebidos pelos senhores ministros do Ultramar e do Exército. ${ }^{33}$

Pelas páginas dos boletins, percebe-se como se tornou comum a presença de equipes da metrópole nas colônias, não somente nas capitais. Portadores de uma suposta mensagem civilizacional e da ideia de fraternidade, nessas visitas os clubes eram recebidos com festas pela população local.

Embaladas pelo contexto, as principais agremiações da metrópole aumentaram sua inserção nos territórios ultramarinos, seja por meio de associação com clubes locais, seja por meio de filiais. A matriz, por vezes, visitava suas congêneres coloniais para celebrar alguma data especial, reforçando assim os laços de fraternidade. ${ }^{34}$

Em algumas dessas oportunidades, a dimensão política tornou-se ainda mais explícita, conforme observado em um comentário sobre uma visita do Sporting de Lisboa para comemorar o $30^{\circ}$ aniversário do Sporting de Bissau. Sem citar o acirrar dos conflitos na Guiné, o chefe da delegação, Doutor Pereira da Silva, na cerimônia de despedida realizada no Ministério do Ultramar, ressaltou "o propósito do seu clube honrar o desporto nacional e de cooperar com o Governo nesta hora de preocupações para o país." ${ }^{35}$ Como de costume, houve a preocupação em demonstrar que se tratava de mais do que um mero encontro recreativo: "o Doutor Pereira da Silva, vice-presidente do clube lisboeta, entregou cerca de 50 livros oferecidos pelo General França Borges, presidente do Município de Lisboa"36

Por vezes, as visitas das equipes da metrópole ocorriam por motivos mais "institucionais", como a realização de campeonatos nacionais, que passaram a ser também promovidos em algumas colônias. Por exemplo, o Campeonato Nacional Feminino de Basquete de 1962, disputado em Luanda, sagrando-se bicampeã uma equipe local, o Sport Lubango e Benfica. ${ }^{37}$

\footnotetext{
${ }^{33}$ Boletim Geral do Ultramar, vol. 38, n. 445, Lisboa, jul. 1962, p. 201. (http://memoria-africa.ua.pt/Library/ Showlmage.aspx?).

${ }^{34}$ Essas estratégias têm repercussões até atualmente. Nas antigas colônias, seque sendo maior o número dos torcedores de equipes de Portugal do que dos locais. Aliás, as filiais seguem ativas. Ligados ao Benfica, por exemplo, existem o Sport Bissau e Benfica (da Guiné-Bissau) e o Clube Desportivo Travadores (de Cabo Verde). O Sporting tem filiais em Angola (5), Moçambique (2), Cabo Verde (4), Guiné-Bissau (1) e São Tomé e Príncipe (2). Já o Porto tem filiais em Angola (3), Guiné-Bissau (4) e Cabo Verde (2).

${ }^{35}$ Boletim Geral do Ultramar. vol. 42, n. 491, Lisboa, maio de 1966, p. 352.

${ }^{36}$ Boletim Geral do Ultramar, vol. 42, n. 492, Lisboa, junho de 1966, p. 363

${ }^{37}$ Boletim Geral do Ultramar, vol. 38, n. 448, Lisboa, outubro de 1962, p. 299
} 
Não era incomum que equipes das colônias se sagrassem vitoriosas em contendas nacionais, por vezes até mesmo em competições disputadas na Europa. Essas ocasiões eram celebradas como sinais de que os territórios ultramarinos estavam integrados e de que Portugal efetivamente contribuíra para sua civilização. Exaltava-se a maior relação entre as partes do Império, a fraternidade lusófona, o investimento na "valorização física e cultural da juventude portuguesa de todas as latitudes".38

Por vezes, essa presença de equipes das colônias na metrópole foi a conquista de uma antiga reivindicação. Por exemplo, a partir de 1965, a Federação Portuguesa de Futebol,

num louvável gesto de lusitanidade, [...] tornou extensiva às províncias ultramarinas a disputa da Taça de Portugal que antes era apenas disputada entre diversos grupos de futebol da Metrópole..$^{39}$

Nesse processo, os clubes europeus, notadamente de futebol, passaram a contratar atletas das colônias. Não chega a surpreender que alguns desses tenham integrado as seleções nacionais portuguesas. No caso do velho esporte bretão, lembremos que, além de Eusébio, também se destacaram o angolano

No caso do velho esporte bretão, lembremos
que, além de Eusébio, também se destaca-
ram o angolano José Águas e o moçambica-
no Mário Coluna

José Águas e o moçambicano Mário Coluna.

Vale ressaltar que houve também trânsito de atletas entre as colônias. Merece menção o primeiro jogo de futebol e o torneio de atletismo disputado entre seleções de Angola e Moçambique, respectivamente em Luanda, em 1965, e Lourenço Marques, em 1966. Alguns clubes também começaram a realizar com mais frequência torneios entre as colônias, por vezes organizados entre as filiais de uma mesma agremiação da metrópole.

Nessa sequência, equipes coloniais, inclusive seleções provinciais, começaram a participar de torneios com e em outras colônias ou países independentes com os quais faziam fronteira. Integrar uma dessas agremiações tornava possível ao atleta um trânsito que era bastante restrito a outros habitantes, ainda mais quando se acirraram os conflitos anticoloniais. Tratava-se de uma aposta arriscada. Por um lado, essa postura demonstrava o propalado respeito pelas coisas locais, ou seja, a convicção de que a metrópole não tolhia, mas incentivava os territórios coloniais. Da mesma forma, convidar equipes e/ou seleções de outros países/colônias, inclusive de nações europeias (como o Chelsea e o Real Madrid, que fizeram excursões por Moçambique e Angola), era também uma oportunidade de Portugal mostrar ao mundo que tanto desenvolvera quanto possuía controle sobre suas províncias. De outro lado, se

${ }^{38}$ Boletim Geral do UItramar, vol. 41, n. 481, Lisboa, julho de 1965, p. 238.

39/bidem. 
o intuito de Portugal era "dar ao mundo [...] um exemplo da sua ação civilizadora", ${ }^{40}$ esse trânsito de equipes também criava condições de gestação de uma identidade própria.

Esse processo se fortalecia com o fato de que algumas colônias começaram a receber e enviar atletas para torneios com países recém-independentes, o que os colocava em contato com ideias distintas. Não surpreende que, em alguns casos, isso tenha desencadeado certa consciência da necessidade de romper os laços coloniais, como observado no depoimento de Bobo Keita, um dos líderes da luta anticolonial na Guiné, ex-jogador da seleção provincial de futebol, o qual afirmou que essas experiências foram determinantes na formação inicial de sua postura revolucionária. ${ }^{41}$

Evidentemente, não era esse o objetivo do regime. Uma notícia, publicada no Boletim Cultural da Guiné, comentando a visita das seleções nacionais de voleibol e handebol a Guiné-Bissau, em 1962, resume alguns dos sentidos e significados dos investimentos portugueses na prática esportiva nas colônias africanas:

\begin{abstract}
Num patriótico e muito louvável intercâmbio desportivo vieram a trazer aos portugueses do Ultramar o fraternal abraço dos portugueses do continente e nessa troca de sentimentos demonstrar ao mundo, mais uma vez, a razão de ser das Províncias de Além-Mar e a unidade e coesão de todos os territórios que constituem a Pátria Lusitana. ${ }^{42}$
\end{abstract}

Inevitavelmente soa como desproporcional a expectativa sobre a capacidade que por ventura teriam as equipes de voleibol e handebol em "demonstrar ao mundo [...] a razão de ser das Províncias de Além-Mar" e, mais ainda, "a unidade e coesão de todos os territórios". No entanto e exatamente por isso, tal exemplo reflete com precisão o uso que o estado e os demais atores coloniais faziam do esporte: a representação de uma "Pátria Lusitana" que atendia à necessidade de manutenção dos territórios ultramarinos sob a égide de Portugal.

\title{
Algumas breves linhas à guisa de conclusão
}

Ao analisar a presença do esporte no Boletim Geral do Ultramar, é possível verificar uma clara mobilização da prática no âmbito da política colonial portuguesa, notadamente a partir da década de 1950, algo eminentemente relacionado ao momento delicado pelo qual Portugal passava nos cenários interno e internacional. As representações são claramente embasadas pelo luso-tropicalismo em voga, apontando-se a necessidade de construção de uma unidade, união e identidade imperial. Tal uso político se manifesta explicitamente de diversas formas. Além daquelas que foram citadas, deve-se lembrar as homenagens aos dirigentes portugueses (como, por exemplo, estádios e campeonatos batizados com seus nomes, inclusive várias "Taças Salazar").

\footnotetext{
${ }^{40}$ Boletim Geral do Ultramar, vol. 38, n. 443, Lisboa, maio de 1962, p. 204.

${ }^{41}$ Para mais informações ver Norberto Tavares de Carvalho, De campo a campo: conversas com o comandante Bobo Keita, Porto, Edição de autor, 2011; Victor Andrade de Melo, "(Des)mobilização para a luta: o esporte como estratégia nos conflitos da Guiné portuguesa (décadas de 50 e 60 do séc. XX)”, In: Métis: história \&cultura, Caxias do Sul, EDUCS, vol. 10, n. 19, jan./jun. 2011, p. 216-222.

${ }^{42}$ Boletim Cultural da Guiné Portuguesa, vol. 17, n. 67, Lisboa, julho de 1962, p. 187.
} 
No Boletim não é possível notar a mobilização do esporte por parte dos que estavam envolvidos com os movimentos de contestação à ordem colonial, uma dimensão identificada por Melo e Bittencourt ${ }^{43}$ e Melo $^{44}$. Entendese que isso ocorra, já que se tratava de um periódico oficial. Todavia, é possível perceber dois elementos que podem ter facilitado tal mobilização: de um lado, a capacidade de envolver e interessar um grande número de pessoas e, de outro, a promoção de um trânsito de indivíduos e ideias que poderia contribuir para semear e desenvolver novas perspectivas de mundo.

${ }^{43}$ Victor Andrade de Melo, Marcelo Bittencourt, "Sob suspeita: o controle dos clubes esportivos no contexto colonial português", Tempo, vol. 18, n. 33, Niterói, 2012, p. 191-215.

${ }^{44} V$ ictor Andrade de Melo, "(Des)mobilização para a luta: o esporte como estratégia nos conflitos da Guiné portuguesa (décadas de 50 e 60 do séc. XX)", In: Métis: história \&cultura, Caxias do Sul, EDUCS, vol. 10, n. 19, jan.jun. 2011, p. 216-222. 